\title{
IN MEMORIAM CLAUDE DUCHATEAUX
}

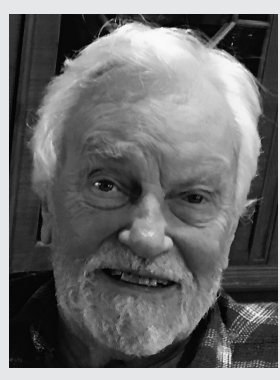

Nous apprenons le décès de Claude Duchateaux, survenu le 5 décembre 2017, dans sa $89^{\mathrm{e}}$ année.

Il assuma la charge de professeur et de chef du département d'orthodontie de la faculté de Nantes. Membre fondateur de l'ARODF en décembre 1968, il en fut le président, de sa fondation à novembre 1993, remplacé ensuite par G. Bounoure.

Il a été rédacteur, animateur des changements d'éditeurs après la faillite de Prélat.

Excellent organisateur, il a été à l'origine d'orientations décisives pour la spécialité. Il a su s'entourer d'enseignants illustres et dispenser une formation de qualité à des générations d'orthodontistes.

Il a marqué la Revue d'ODF de son empreinte.

L'ARODF présente ses plus sincères condoléances à sa famille et à ses proches.

Guy M. Bounoure Président de l'ARODF 